\title{
CARACTERIZACIÓN DEL FRUTO Y LA SEMILLA DE RUPRECHTIA APETALA (POLYGONACEAE) EN RELACIÓN CON LA ENTRADA DE AGUA Y LA GERMINACIÓN
}

\author{
MARÍA S. DIAZ1 \& MARÍA L. MOLINELLI²
}

\begin{abstract}
Summary: Diaz, M. S. \& M. L. Molinelli. 2017. Characterization of Ruprechtia apetala (Polygonaceae) fruit and seed in relation to water intake and germination. Bonplandia 27(1): 5-22.
\end{abstract}

\begin{abstract}
Ruprechtia apetala Wedd. (Polygonaceae), "field apple", is a tree native to South America, cited as ornamental, medicinal and for reforestation. The objectives of this work were to characterize the fruit and seed morphology, to determine the water entry area, and to evaluate seed germination. Fruits were collected in Luyaba (Córdoba, Argentina). Histological sections and stains followed standard protocols, and observations were made with light and stereoscopic microscopy. Germination was evaluated in achenes with sepals, achenes without sepals, and seeds sensu stricto, at $25^{\circ} \mathrm{C}$ or $20<=>30^{\circ} \mathrm{C}$, with photoperiod of $8 / 16 \mathrm{~h}$ or permanent darkness. The results showed that fruits have an epicarp with non-lignified macroesclerides and tannins in their lumen, the mesocarp has 4-8 layers of parenchyma, and the endocarp has a single layer. Seeds have an episperm with papillose pattern, an amyloid and ruminated endosperm, and a foliated and folded embryo in axial position. Epistasis and hypostasis were observed. Water entrance occurs through the remains of the style in the achene or through the episperm in the seed. The maximum germination percentage $(84 \%)$ was obtained both in achenes with sepals and in those without sepals at $20<=>30^{\circ} \mathrm{C}$, with a photoperiod $8 / 16 \mathrm{~h}$. It was shown that sepals and pericarp do not affect germination.
\end{abstract}

Key words: Achene, imbibition, morphology, native tree, Ruprechtia apetala.

Resumen: Diaz, M. S. \& M. L. Molinelli. 2017. Caracterización del fruto y la semilla de Ruprechtia apetala (Polygonaceae) en relación con la entrada de agua y la germinación. Bonplandia 27(1): 5-22.

Ruprechtia apetala Wedd. (Polygonaceae), "manzano del campo", es un árbol nativo de Sudamérica, citado como ornamental, medicinal y para reforestación. Los objetivos de esta investigación fueron caracterizar la morfología del fruto y la semilla, determinar la zona de entrada de agua y evaluar la germinación. Se recolectaron frutos en Luyaba (Córdoba, Argentina). Se realizaron cortes histológicos, tinciones y observaciones con microscopio óptico y estereoscópico. Se evaluó la germinación de aquenios con sépalos, aquenios sin sépalos y semillas sensu stricto, a $25^{\circ} \mathrm{C} \circ 20<=>30^{\circ} \mathrm{C}$, con fotoperíodo de $8 / 16 \mathrm{~h}$ u oscuridad permanente. Los resultados mostraron que el fruto posee epicarpo con macroesclereidas no lignificadas y taninos en el lumen, mesocarpo con 4-8 capas de parénquima y endocarpo unistrato. Las semillas muestran episperma con patrón papiloso, endosperma amiláceo y ruminado, y embrión foliado y plegado en posición axial. Se observó epístasis e hipóstasis. La entrada de agua comienza por los restos de los estilos del aquenio y en la semilla por el episperma. El máximo

${ }^{1}$ CEPROCOR. Santa María de Punilla. Córdoba. Argentina. E-mail: soledaddiaz81@gmail.com

${ }^{2}$ CREAN-IMBIV-CONICET-UNC. Facultad de Ciencias Agropecuarias. Universidad Nacional de Córdoba. Ciudad Universitaria. 5000. Córdoba. Argentina. 
porcentaje de germinación (84\%) se obtuvo tanto en los aquenios con sépalos como en aquellos sin sépalos a $20<=>30^{\circ} \mathrm{C}$, con un fotoperíodo $8 / 16 \mathrm{~h}$. Se demostró que los sépalos y el pericarpo no afectan la germinación.

Palabras clave: Aquenio, árbol nativo, imbibición, morfología, Ruprechtia apetala.

\section{Introducción}

\section{Ruprechtia apetala Wedd. (Polygonaceae)} es conocida con los nombres vulgares de "manzano del campo", "manzanito", "marmelero", "higuerón”, “duraznillo", "duraznillo blanco", "sacha-mansa", "virarú", "chuluco" o "ivirá puitá-y" entre otros (de la Peña \& Pensiero, 2004). Este árbol nativo de Sudamérica, crece desde Bolivia hasta el noroeste de Paraguay, en el norte y centro de Argentina y en el este de Brasil (Zuloaga et al., 2011; Melo, 2015; GBIF 2016). En Argentina, el área de distribución de esta especie comprende la provincia fitogeográfica Chaqueña, en particular, en las zonas secas y montañosas del bosque nativo de los distritos occidental y serrano (Cabrera, 1971; Cocucci, 1997). En las últimas décadas, esta región es la que recibe mayor impacto tanto por la explotación forestal como por la expansión de la frontera agropecuaria, con la consecuente disminución de la superficie del bosque nativo (Morello \& Rodríguez, 2009; UMSEF, 2016). Específicamente en las sierras chicas de Córdoba, debido a la pérdida y fragmentación del bosque serrano la situación de conservación deberá considerarse amenazada en lugar de vulnerable (Gavier \& Bucher, 2004). En este sentido, $R$. apetala está registrada en la categoría Bajo Riesgo, subcategoría Casi Amenazada de La Lista Roja, dado que crece en áreas muy degradadas por la deforestación y el sobrepastoreo (IUCN, 2017).

Las características morfológicas de $R$. apetala fueron descriptas por Cocucci (1961, 1997) y por Parodi (1978). Es una especie arbórea dioica (Fig. 1A-C), inerme y con ramaje nudoso, las hojas son semipersistentes, de consistencia coriácea y coloración verderojiza. Los frutos son aquenios piriformes acompañados por tres sépalos acrescentes de tonos cobrizos, permanecen en el árbol durante un largo período (Fig. 1D) y constituyen la unidad de dispersión por anemocoria (Demaio et al., 2002; Abraham de Noir \& Bravo, 2014).

La estructura y sus cualidades ornamentales, junto a la capacidad de desarrollarse en laderas pedregosas le brindan condiciones apropiadas tanto para su uso paisajístico en espacios verdes urbanos, como para la reforestación y el control de la erosión (Césere et al., 1998; Volkmann \& Suarez, 2008; Pons, 2015). Además se la menciona como especie apícola y tintórea por los colorantes obtenidos de las astillas de madera y de la corteza (Verzino et al., 2016). Asimismo, se emplea su madera en la elaboración de utensilios domésticos (Demaio et al., 2002) y su corteza para fines medicinales debido sus propiedades diuréticas (Del Vitto et al., 1997; Núñez \& Cantero, 2000; Barboza et al., 2006).

Existe información sobre los diferentes tipos de frutos de las Polygonaceae en el trabajo de Spjut (1994). La morfología de la semilla fue descripta en forma general por Werker (1997) y Evert (2006), mientras que las características internas (embrión y endosperma) de la semilla de la familia, fueron analizadas por Martin (1946). Según Corner (1976), el conocimiento de las semillas de las Polygonaceae es escaso, debido a que los frutos son indehiscentes.

Por otro lado, la mayoría de las investigaciones en semillas de la familia se han realizado en especies cultivadas, mientras que las semillas de los árboles, especialmente nativos, fueron menos investigadas (Niembro Rocas, 1989; Maiti et al., 2016). Estudios en la drupa de Olea europaea L. y en la semilla de Ribes multiflorum Kit. ex Roem. \& Schult. subsp. sandalioticum Arrig. son ejemplos de especies cultivadas en las que se identificó la entrada del agua empleando distintas soluciones (Voyiatzis, 1992; Mattana et al., 2012).

Respecto a $R$. apetala, se han realizado estudios vinculados a la domesticación y a los requerimientos de germinación en vivero y a 

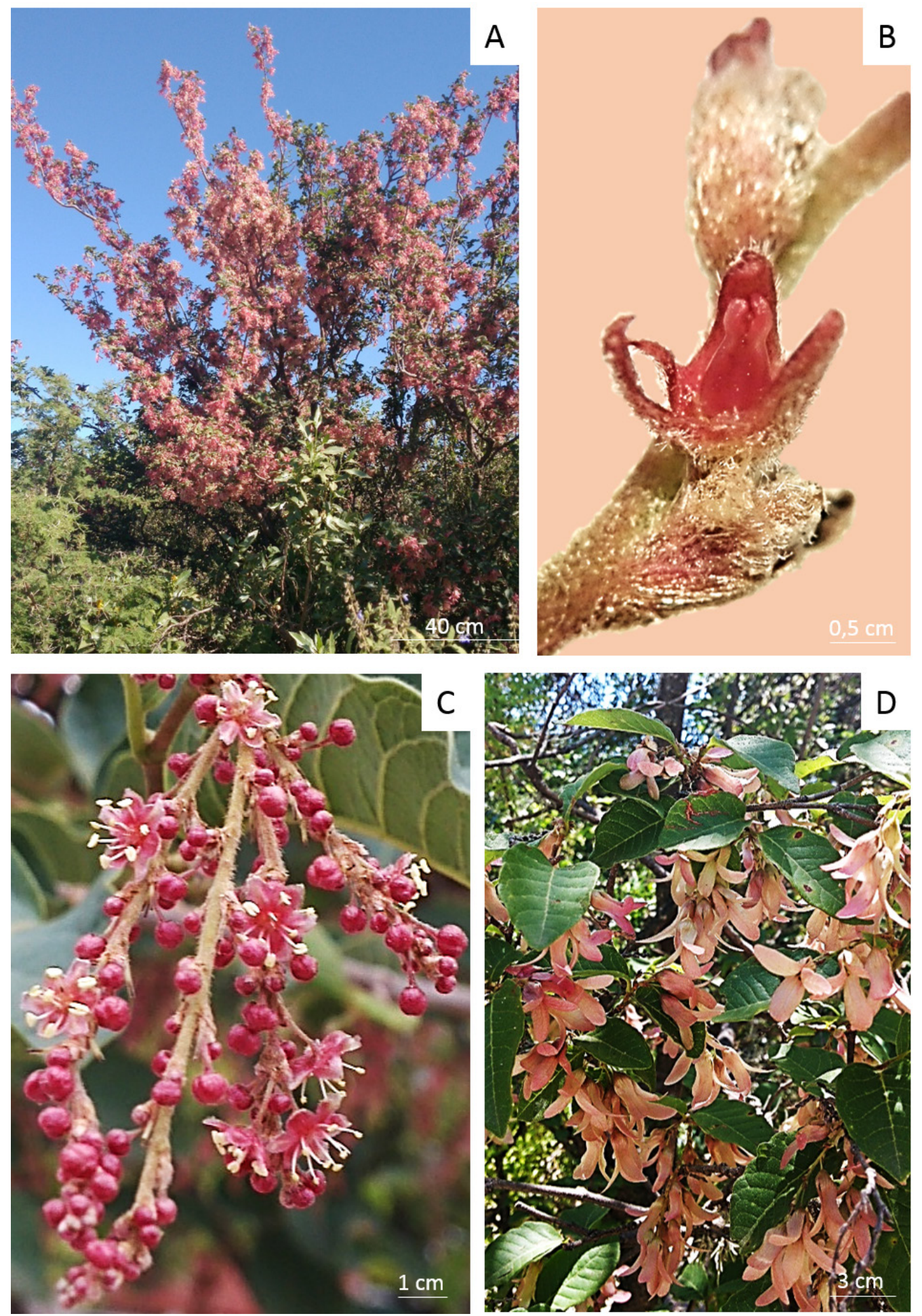

Fig. 1. Ruprechtia apetala. A: Vista general del árbol en fructificación. B: Flores femeninas en distinto estado de desarrollo. C: Inflorescencia racemosa masculina. D: Ramas fructíferas.

Fig. 1. Ruprechtia apetala. A: General view of the tree in fruiting. B: Female flowers in different stages of development. C: Male racemose inflorescence. D: Fruitful branches. 
campo (Joseau et al., 2013). Además, se ha comprobado que se obtienen porcentajes de germinación nulos con temperaturas inferiores a $15^{\circ} \mathrm{C}$, pero se logran valores mayores al $60 \%$ cuando la temperatura es superior a $25^{\circ} \mathrm{C}$, independientemente de las condiciones lumínicas (Funes et al., 2009; Pais Bosch et al., 2012). Baskin \& Baskin (2014) indican que la alternancia de temperatura es más favorable que la temperatura constante.

Diversas investigaciones (Alzugaray et al., 2007; Marino et al., 2008; Alzugaray \& Carnevale, 2009) desarrolladas en otras especies de Ruprechtia, como $R$. laxiflora Meisn. describen los requerimientos pregerminativos, la germinación, el vigor $\mathrm{y}$ los caracteres morfológicos de las plántulas; mientras que en $R$. fusca Fernald, Soriano et al. (2011) analizaron la relación existente entre el tamaño de la semilla y la composición de sus reservas con la germinación.

Con el fin de optimizar los resultados de los ensayos de germinación en el laboratorio, es muy común la aplicación de pretratamientos como la escarificación y la extracción de las estructuras extraováricas, para disminuir el efecto negativo del tegumento seminal y del pericarpo. Baskin \& Baskin (2001) sugirieron que la extracción del pericarpo, en el caso de las unidades de dispersión en las cuales interviene el fruto, puede modificar los porcentajes de germinación. También, Baskin \& Baskin (2014) mencionan los riesgos y beneficios de utilizar las unidades de dispersión intactas.

En este contexto, los objetivos del trabajo fueron caracterizar la morfología del fruto y la semilla de $R$. apetala, determinar la zona de entrada del agua y evaluar la germinación.

\section{Materiales y Métodos}

\section{Material vegetal}

Se cosecharon manualmente frutos de $R$. apetala de una población de árboles de la localidad de Luyaba, Dep. San Javier, Prov. de Córdoba, Argentina en diciembre de 2013. Fueron conservados en bolsas de papel a temperatura ambiente hasta la realización de las observaciones morfológicas y del ensayo de germinación. También fueron recolectadas muestras de material vegetal que se acondicionaron, herborizaron, catalogaron y depositaron en el Herbario de la Facultad de Ciencias Agropecuarias de la Universidad Nacional de Córdoba (ACOR): Ruprechtia apetala Wedd. ARGENTINA. Prov. Córdoba, Dep. San Javier: Luyaba, $32^{\circ} 20^{\prime} \mathrm{S}, 65^{\circ} 30^{\prime} \mathrm{W}$, 688 m s.n.m., 15-VI-2014, Diaz 1044 (ACOR); ibíd., Diaz 1045 (ACOR).

Caracterización morfológica del fruto y la semilla

En la descripción del fruto se tuvieron en cuenta los criterios de Spjut (1994), mientras que las características generales de la semilla, las del embrión y las del endosperma fueron descriptas según Martin (1946) y Corner (1976). Para determinar el color de los sépalos, el pericarpo y la cubierta seminal se compararon frutos maduros y semillas con la carta de colores de Munsell (2000). Los datos de la longitud de los frutos y las semillas se obtuvieron a partir de 2 repeticiones de 25 unidades. El peso de 1000 aquenios se obtuvo según "International Seed Testing Association" (ISTA, 2017).

Para los estudios anatómicos del fruto y la semilla se realizaron preparados permanentes mediante el método de inclusión en parafina según Zarlavsky (2014). Los frutos incluidos en parafina fueron cortados en secciones transversales con micrótomo rotatorio $(6-8 \mu \mathrm{m})$, se tiñeron con safranina $\mathrm{y}$ verde rápido. También fueron efectuados preparados semipermanentes, los cuales se colorearon con safranina y azul astral. Los preparados permanentes fueron montados en bálsamo de Canadá y los semipermanentes en glicerina-agua destilada 1:1. Para las pruebas histoquímicas se siguieron las técnicas descriptas por Zarlavsky (2014) y se utilizaron los siguientes reactivos y colorantes: para determinar la presencia de almidón, reactivo de Lugol; lípidos, Sudán III; proteínas en la capa de aleurona, azul de Coomassie; lignina, floroglucina $1 \%$ en alcohol etílico $96^{\circ}$; taninos, sulfato férrico en formol 10\%.

Para el estudio de la epidermis de los sépalos se siguió la técnica de peeling descripta por (Zarlavsky, 2014). Las mediciones fueron efectuadas con un micrómetro de ocular en el 
tercio medio de ambas caras, de cuatro sépalos correspondientes a distintos frutos. Las medias y desviaciones estándares corresponden a la longitud de 40 tricomas. Estos fueron clasificados en cortos y largos, según su longitud: menor o igual a $100 \mu \mathrm{m}$ y mayor a $100 \mu \mathrm{m}$, respectivamente.

Las medias y desviaciones estándares de las células del epicarpo y del episperma, fueron calculadas sobre 20 mediciones. Las observaciones y fotografías se realizaron con un microscopio estereoscópico Zeiss Stemi DV4 y un microscopio Nikon Eclipse E 400.

\section{Zona inicial de entrada de agua}

Para determinar el sitio inicial de entrada de agua se aplicó una metodología adaptada de las técnicas propuestas por Voyiatzis (1992) y Gama-Arachchige et al. (2013). Para ello, fueron sumergidos 10 frutos en verde rápido saturado en alcohol etílico $96^{\circ}$ a temperatura ambiente. Se realizó la observación de la tinción retirando los frutos a las $24 \mathrm{~h}$ y a los 15 días. Luego, fueron lavados con agua y secados con papel absorbente tipo tissue con el fin de extraer el exceso superficial del colorante. Otros 10 frutos fueron sumergidos en agua destilada y se observaron a las $24 \mathrm{~h}$. Posteriormente, fueron realizados cortes a mano alzada longitudinales y transversales. Las observaciones y fotografías se realizaron con un microscopio estereoscópico Zeiss Stemi DV4.

\section{Ensayos de germinación}

Se evaluó el porcentaje de germinación y se analizó la influencia de las estructuras extraováricas que acompañan a la semilla de $R$. apetala. Fueron considerados los aquenios con sépalos: ACS (frutos intactos, con los sépalos persistentes), aquenios sin sépalos: ASS (frutos con remoción manual de los sépalos) y semillas sensu stricto: SE (extracción del pericarpo con la ayuda de pinzas histológicas).

Previo a la siembra, el material fue desinfectado con una solución de hipoclorito de sodio al 5\%, durante $5 \mathrm{~min}$ y, posteriormente, fue enjuagado con agua destilada. La siembra fue realizada en papel Valot ${ }^{\circledR}$ humedecido con agua destilada, se formaron rollos y fueron colocados dentro de bolsas plásticas para mantener la humedad. El ensayo se llevó a cabo en cámaras de germinación. Los tratamientos fueron, temperatura constante de $25^{\circ} \mathrm{C}$ y alternante de $20<=>30^{\circ} \mathrm{C}$, combinadas con oscuridad permanente (OP) y fotoperíodo de 8 h de luz y 16 h de oscuridad (L/O 8/16h). La OP se simuló cubriendo los rollos con papel de aluminio, que se dispusieron en doble bolsa de polietileno negro.

A través de observaciones realizadas diariamente, durante 35 días, se determinó una curva de germinación en función del tiempo. La semilla fue considerada germinada cuando presentó al menos $2 \mathrm{~mm}$ de radícula emergida (germinación fisiológica).

\section{Análisis estadístico}

Las unidades experimentales fueron de 25 semillas cada una con cuatro repeticiones para cada combinación de variables. Se siguió un diseño completamente aleatorizado y los datos se analizaron mediante ANOVA trifactorial, utilizando el programa InfoStat (Di Rienzo et al., 2013). Las comparaciones entre las medias se realizaron con la prueba LSD de Fisher $(\mathrm{P}<0,05)$.

\section{Resultados y Discusión}

\section{Caracterización morfológica}

Exomorfología del fruto. El aquenio de $R$. apetala se caracteriza por presentar sépalos acrescentes pubescentes en el fruto inmaduro (Fig. 2 A-B). En el fruto maduro, disminuye la cantidad de tricomas y los sépalos adquieren un color rojo 10R (4/6) (Fig. 2C). La longitud promedio del aquenio con sépalos es de 3,2 cm y el peso de 1000 frutos es 29,70 g. Según Abraham de Noir \& Bravo (2014), la presencia del cáliz acrescente y el peso reducido de los frutos son caracteres que favorecen la dispersión anemócora. En este sentido, Werker (1997) aclara que si bien la mayoría de las estructuras aladas se dispersan mediante el viento, las alas también pueden favorecer la flotabilidad de los frutos.

El aquenio de $R$. apetala es trígono de forma piramidal o piriforme y el pericarpo es de color marrón 7,5 YR (5/4), glabro y de superficie lisa (Fig. 2D). Mide de $7 \mathrm{~mm}$ a 1 


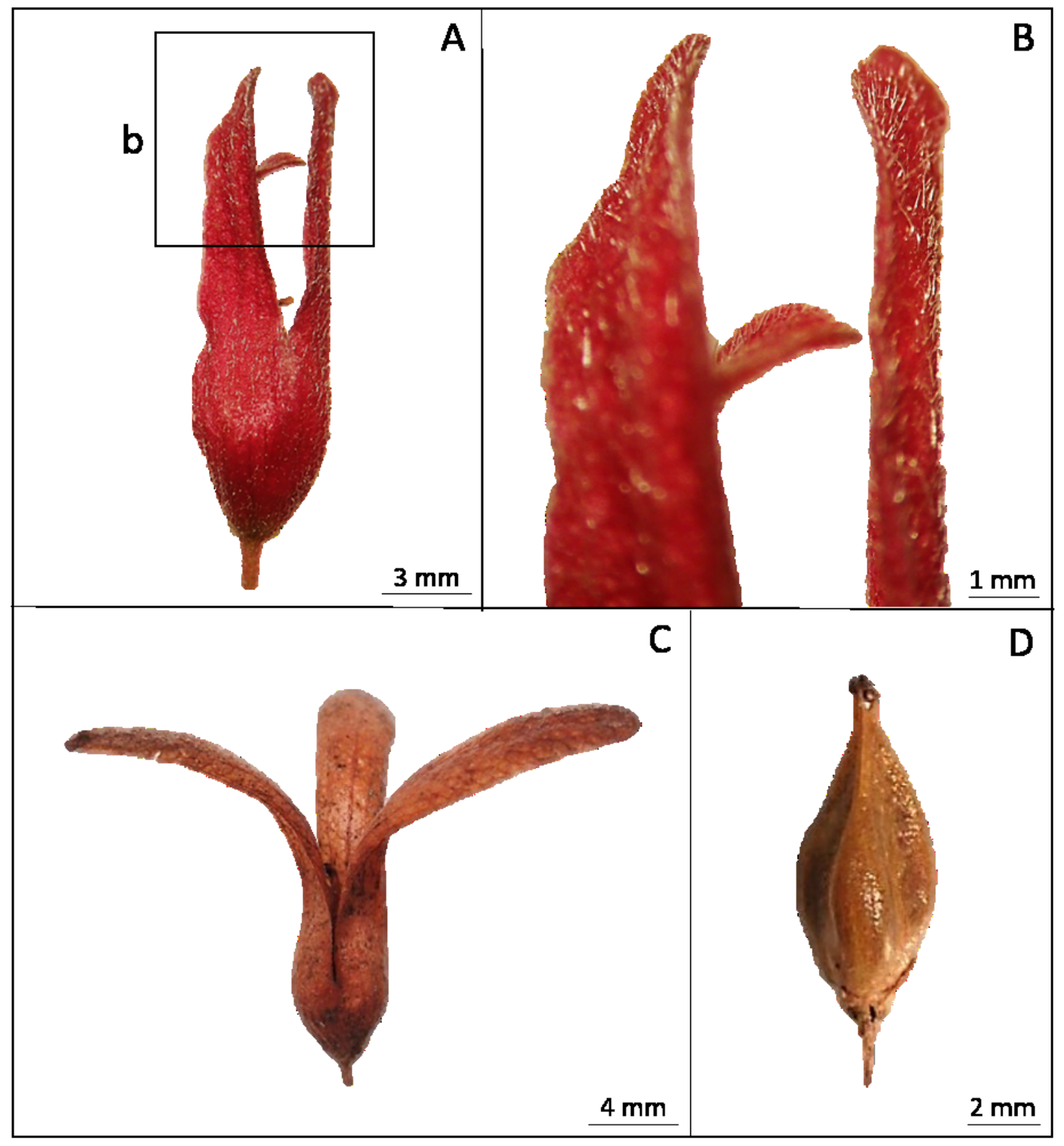

Fig. 2. Fruto de R. apetala. A: Vista externa del fruto inmaduro con sépalos acrescentes. B: Detalle de recuadro marcado en A, mostrando los sépalos pubescentes. C: Fruto maduro con sépalos persistentes. D: Aquenio sin sépalos.

Fig. 2. Fruit of $R$. apetala. A: External view of the immature fruit with accresent sepals. B: Detail of box marked in A, showing the pubescent sepals. C: Mature fruit with persistent sepals. D: Achene without sepals.

cm de longitud y de 3 a 4 mm de ancho. Estos caracteres concuerdan con Cronquist (1977), quien menciona que los aquenios son frutos pequeños y rara vez alcanzan más de $1 \mathrm{~cm}$ de longitud.

Según Spjut (1994), la pseudosámara o falsa sámara es un tipo de fruto alado cuyo perianto acrescente posee alas distales de longitud 2 o más veces mayor que el pericarpo como se observa en algunas Polygonaceae. Si se considera que el fruto de $R$. apetala tiene sépalos persistentes que participan como alas 
en el mecanismo de dispersión (Abraham de Noir \& Bravo, 2014) el término pseudosámara, también se puede aplicar en este caso.

Anatomía de los sépalos que acompañan al fruto. Presentan epidermis uniestratificada, con células de forma rectangular a redondeada en transcorte (Fig. 3A). Ambas epidermis presentan tricomas simples, unicelulares cortos y largos. Los tricomas cortos miden $77 \pm$ $13 \mu \mathrm{m}$ y los largos $155 \pm 42 \mu \mathrm{m}$ (Fig. 3B). En los sépalos maduros, los tricomas se caen con la consecuente disminución de la pubescencia. El mesofilo está formado por 5-7 capas de parénquima esponjoso laxo, los haces vasculares son colaterales y, además, el haz vascular central está rodeado por fibras (Fig. 3A).

Anatomía del fruto y pericarpo. El aquenio es tricarpelar y, en transcorte, posee un contorno trilobado y la zona de unión de los carpelos coincide con los extremos de los lóbulos (Fig. 4A-B). El epicarpo está compuesto por una capa de esclereidas, células columnares $80 \pm$ $16 \mu \mathrm{m}$ de longitud, con las paredes radiales rectas a levemente onduladas en el fruto joven, que se van engrosando conjuntamente con la pared tangencial externa, a medida que se produce la maduración del fruto (Fig. 4C-D). Evert (2006) describe células similares, como esclereidas alargadas, de paredes secundarias muy densas que ocluyen el lumen, ordenadas en una capa continua en empalizada y las denomina macroesclereidas. Werker (1997) indica que las esclereidas del pericarpo pueden constituir la principal capa de protección de la semilla, en las especies donde los frutos constituyen la unidad de dispersión, como es el caso del aquenio de $R$. apetala.

Las macroesclereidas son células con paredes secundarias celulósicas o lignificadas (Fahn, 1978; Esau, 1982), en el episperma de Pisum sativum L. no están lignificadas (Evert, 2006). La reacción con floroglucina en las macroesclereidas del aquenio de $R$. apetala resultó negativa, lo que indica que no están lignificadas. El lumen de las macroesclereidas tiene forma triangular hacia la pared tangencial interna, y forma un canal longitudinal en el centro de la célula que se ramifica hacia la pared tangencial externa (Fig. 4E).

En el lumen se hallaron taninos que dieron reacción positiva a la tinción con sulfato férrico, con un color pardo negro (Fig. 4E-F). Werker (1997) y Evert (2006) explican que los taninos,

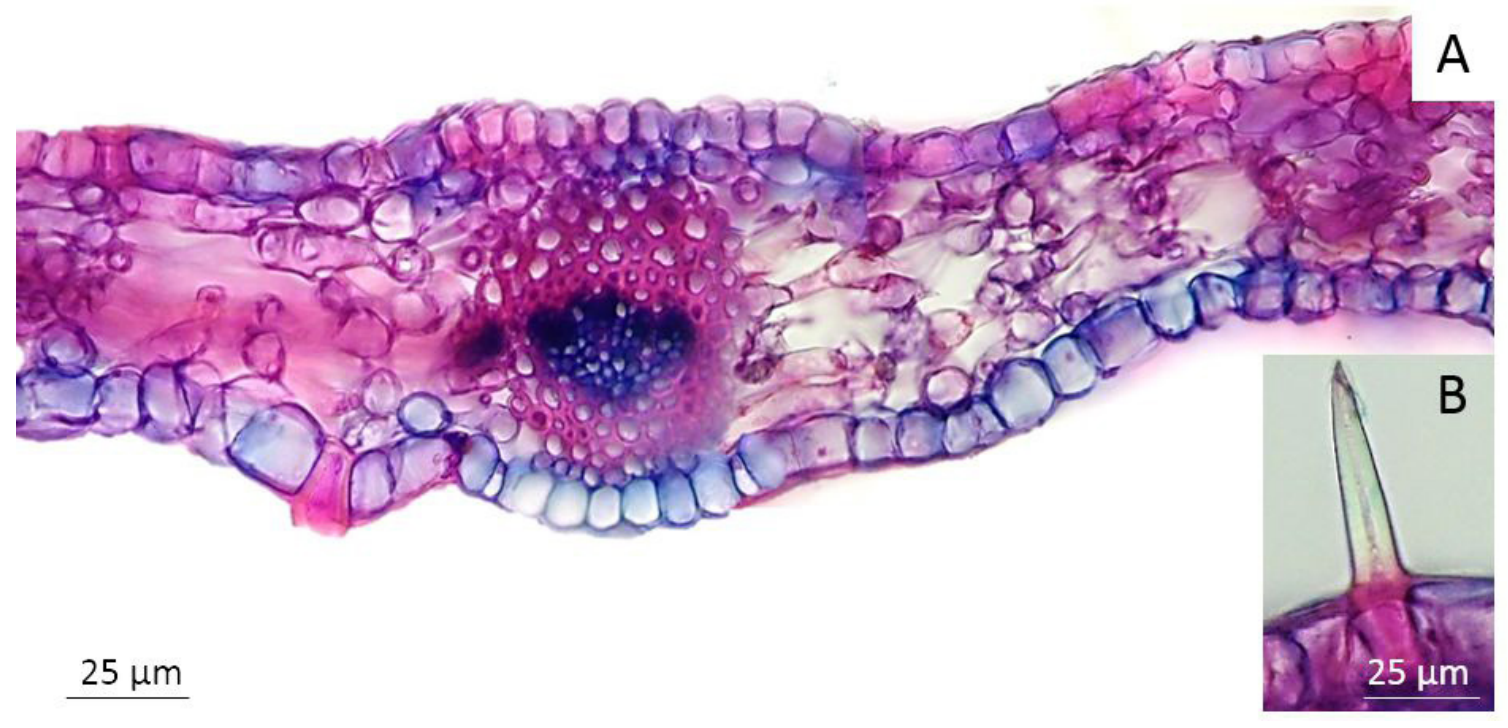

Fig. 3. Anatomía del sépalo de $R$. apetala. A: Corte transversal del sépalo con haz vascular central rodeado por fibras. B: Tricoma simple.

Fig. 3. Anatomy of the sepal of $R$. apetala. A: Transverse section of the sepal with central vascular bundle surrounded by fibers. B: Simple trichome. 

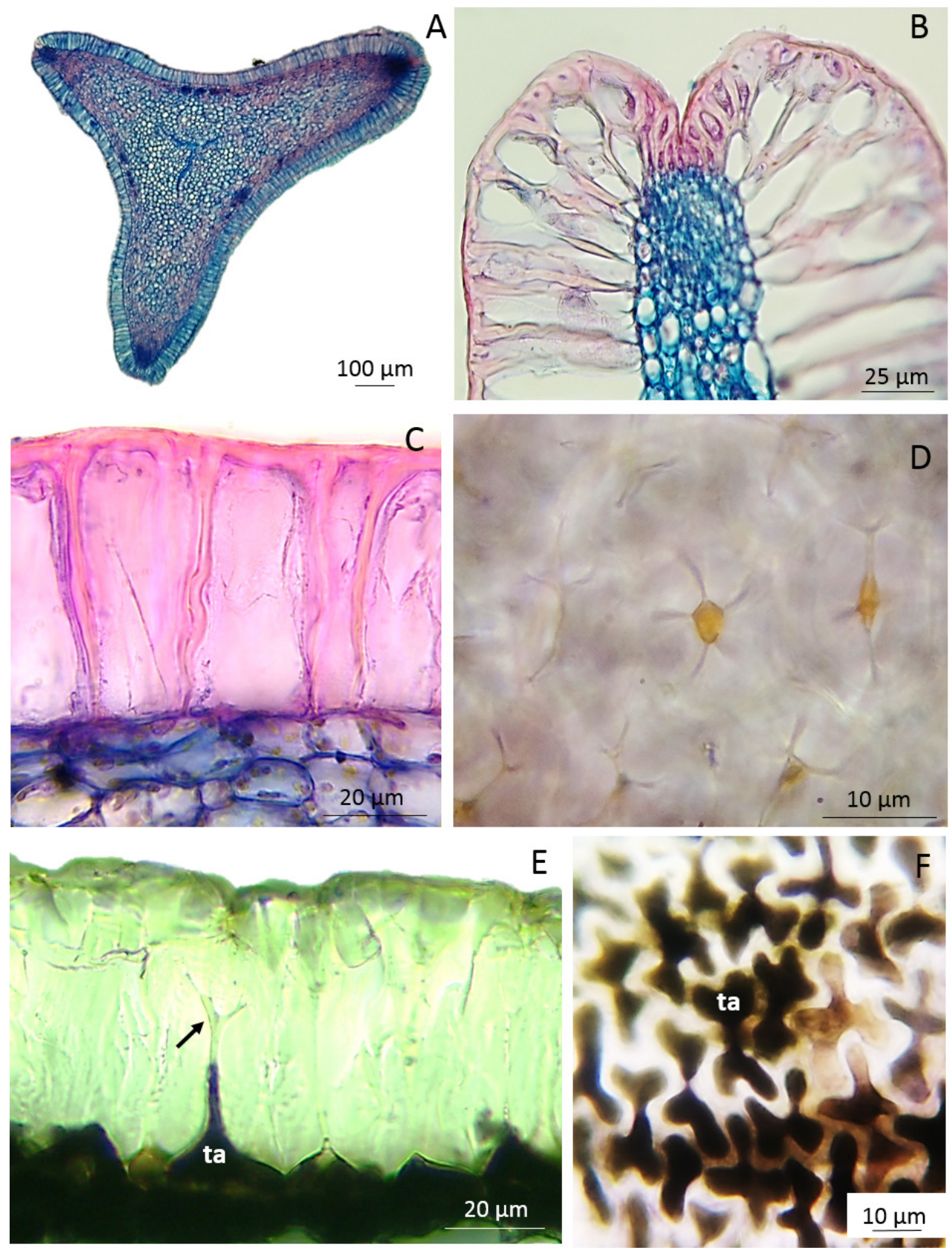

Fig. 4. Anatomía del fruto de R. apetala. A-C: fruto inmaduro. D-F: fruto maduro. A: Corte transversal de aquenio con contorno trígono. B: Detalle de un lóbulo del fruto, en la zona de unión de los carpelos. C: Corte transversal del pericarpo con esclereidas de paredes radiales delgadas. D: Vista superior de las macroesclereidas del pericarpo, con paredes tangenciales externas engrosadas y el lumen ocluido. E: Corte transversal de macroesclereidas con taninos (ta), la flecha indica el canal longitudinal ramificado. F: Vista tangencial de las macroesclereidas, se observa la zona basal ensanchada, ocupada por taninos.

Fig. 4. Anatomy of the fruit of $R$. apetala. A-C: immature fruit. D-F: mature fruit. A: Achene cross section with trigonous outline. B: Detail of the fruit lobe, in the union area of the carpels. C: Transverse section of the pericarp with sclereids with thin radial walls. D: Top view of the pericarp macrosclereids, with thickened external tangential walls and the occluded lumen. E: Cross section of macroesclereids with tannins (ta), the arrow indicates the longitudinal branched channel. F: Tangential view of the macrosclereids, the widened basal zone is observed, occupied by tannins. 
sirven para la repulsión de los herbívoros, la protección contra los hongos, las bacterias y los virus. Además indican que actúan en la impermeabilidad al agua, con el consecuente impedimento de la imbibición del embrión y también le atribuyen la capacidad de colorear el aquenio.

El mesocarpo está constituido por 4-8 capas de clorénquima, con las células pequeñas y alargadas tangencialmente o algo isodiamétricas, gradualmente, hacia las capas más internas las células adoptan forma redondeada, aumentan su tamaño y son incoloras (Fig. 5A). En estas primeras capas se encuentran los haces vasculares, distribuidos en número de tres en cada valle y un haz vascular de mayor tamaño en cada costilla. En la zona del parénquima incoloro se observan drusas (Fig. 5B). El número total de capas del mesocarpo varía acompañando las hendiduras del aquenio trígono.

El endocarpo está compuesto por una capa de células redondeadas o alargadas, y en algunas zonas se pliega para acompañar la forma trígona de la semilla (Fig. 5C).

En relación al tamaño del aquenio de Ruprechtia, Cocucci (1961) afirma que a medida que el fruto madura, el ovario aumenta de volumen significativamente, en relación con el escaso aumento de tamaño del óvulo, por lo cual se acumulan reservas en el pericarpo. En el presente trabajo, la tinción con Lugol demostró escasa cantidad de almidón (Fig. 5D).

En el fruto maduro se mantienen las macroesclereidas del epicarpo pero, el mesocarpo se reduce a 1-3 capas de células en la zona de los valles y 4-6 capas en la zona de las costillas. En el endocarpo no se observan restos celulares.

Exomorfología de la semilla. La semilla deriva de las diversas transformaciones del óvulo ortrótopo luego de la fecundación. Es trígona (Fig. 6A), de forma piramidal o piriforme y con cicatriz del funículo y del micrópilo opuestas (Fig. 6B). Mide 5-7 mm de largo y 3-3,5 $\mathrm{mm}$ de ancho. La superficie externa de la cubierta seminal muestra un patrón papiloso, debido a la protrusión leve de la pared tangencial externa convexa, de las células del episperma. Las invaginaciones observadas en la cubierta seminal unistrata permiten clasificar a la semilla de Ruprechtia dentro del tipo Coccoloba, según la clasificación de Periasamy (1962).

El tejido de reserva de la semilla exhibe endosperma amiláceo ruminado (Fig. 6A-C), coincidiendo con lo informado por Cocucci (1961) para el género Ruprechtia. Con respecto al embrión, se observa la radícula conspicua, ubicada con su meristema apical radical hacia el micrópilo, y los cotiledones foliáceos ampliamente expandidos hacia dos de los vértices del aquenio y plegados en sentido transversal (Fig. 6A, D-E). Estas características concuerdan con aquellas informadas por Martin (1946) para las Polygonaceae, quien clasifica a este tipo de embrión según su ubicación en la división Axial, subdivisión Foliado, tipo Plegado.

Anatomía de la semilla. El episperma está constituido por una hilera de células cuboides de paredes delgadas que miden $77 \pm 15 \mu \mathrm{m}$ de alto, y no se observan tricomas ni estomas (Fig. 7A-B). Según Werker (1997), este tipo de células son típicas del episperma de las semillas que se dispersan con el viento o con el agua, ya que las paredes delgadas y el tamaño celular grande son características que contribuyen a la baja densidad. Además, menciona que la cubierta seminal delgada es propia de semillas que se encuentran dentro de un fruto indehiscente, como es el caso del aquenio de $R$. apetala. En la zona del micrópilo y del funículo se observa la epístasis e hipóstasis respectivamente, ambas con contenidos tánicos, coincidiendo con lo observado por Corner (1976). A continuación del episperma, se encuentran 2 a 3 hileras de células con cloroplastos, seguidas por una capa de aleurona (1 a 5 hileras de células) rodeada por una delgada cutícula. Las proteínas de la capa de aleurona reaccionaron positivamente a la tinción con azul de Coomasie (Fig. 7D). La presencia de la capa de aleurona ya fue mencionada para las Polygonaceae por Werker (1997). El endosperma amiláceo está formado por células grandes, de paredes delgadas que contienen amiloplastos que se tiñeron con Lugol (Fig. 7C). En el embrión, se observan cristales estrellados (drusas) en el mesofilo de los cotiledones (Fig. 7E). 

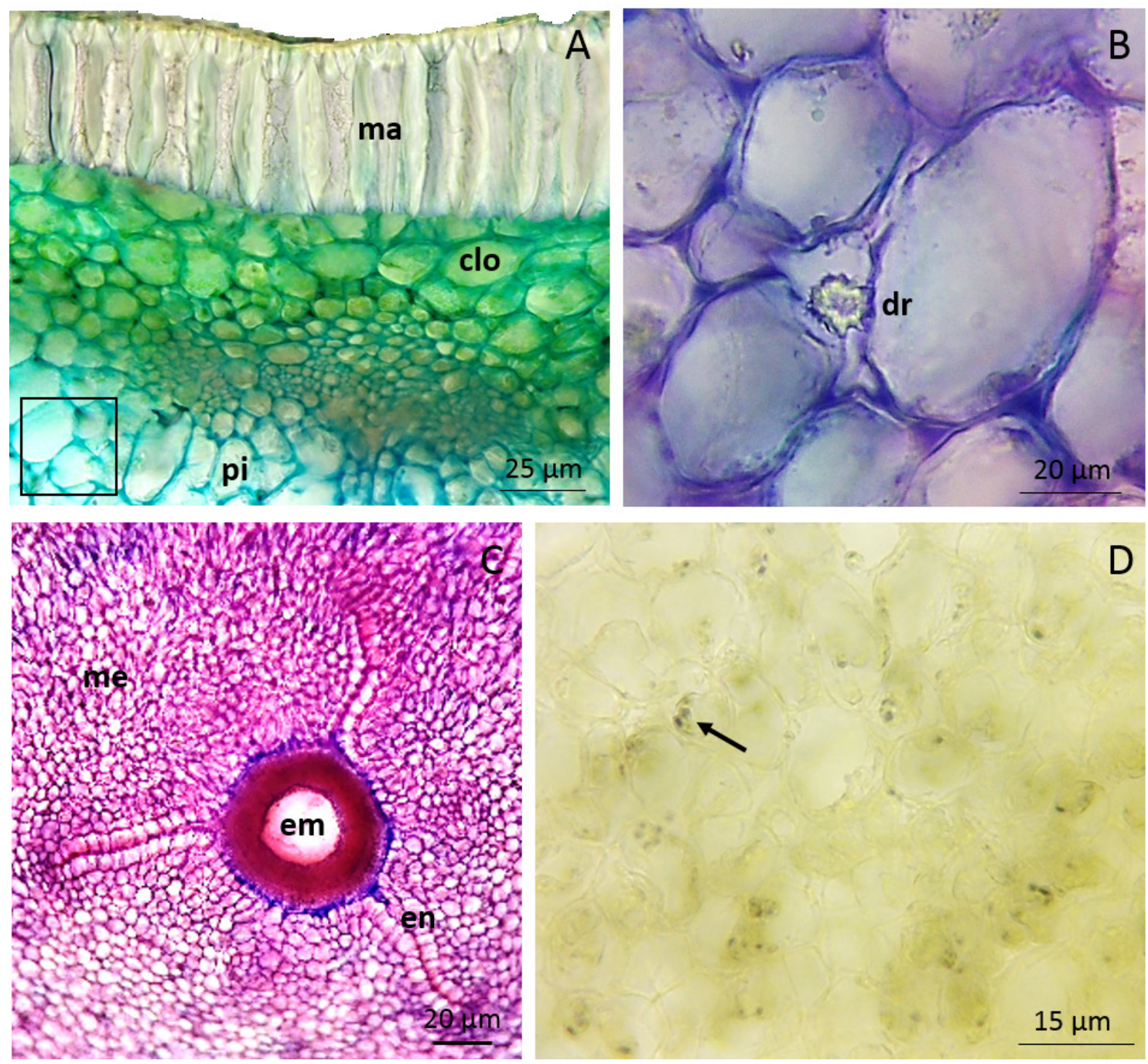

Fig. 5. Pericarpo del aquenio de $R$. apetala en corte transversal. A: Epicarpo con macroesclereidas (ma), mesocarpo con clorénquima (clo) y parénquima incoloro (pi). B: Detalle del recuadro en A, parénquima incoloro del mesocarpo con presencia de drusas (dr); C: Mesocarpo (me) y endocarpo (en) plegado, en el centro se observa el embrión (em). D: Células del mesocarpo con escasas reservas (amiloplasto indicado con flecha).

Fig. 5. Pericarp of the achene of $R$. apetala in cross section. A: Epicarp with macroesclereids (ma), mesocarp with chlorenchyma (clo) and colorless parenchyma (pi). B: Detail of the box in A, colorless parenchyma of the mesocarp with presence of druses (dr); C: Mesocarp (me) and endocarp (en) folded, in the center the embryo (em) is observed. D: Mesocarp cells with scarce reserves (amiloplast indicated with arrow).

\section{Zona inicial de entrada del agua}

Las observaciones realizadas en los frutos retirados a las $24 \mathrm{~h}$ de inmersión en la solución de verde rápido, ponen en evidencia que el ingreso de agua ocurre por los restos de los tres estilos al comienzo de la imbibición (Fig. 8A). En la zona de la sutura de los carpelos que conforman cada estilo existe una discontinuidad en la capa de macroesclereidas del epicarpo (Fig. 8B). Así, se forman tres aberturas apicales a través de las cuales ingresa el agua, que permiten superar el bloqueo causado por las macroesclereidas en empalizada del pericarpo. Los cortes longitudinales del estilo muestran que las células alargadas 


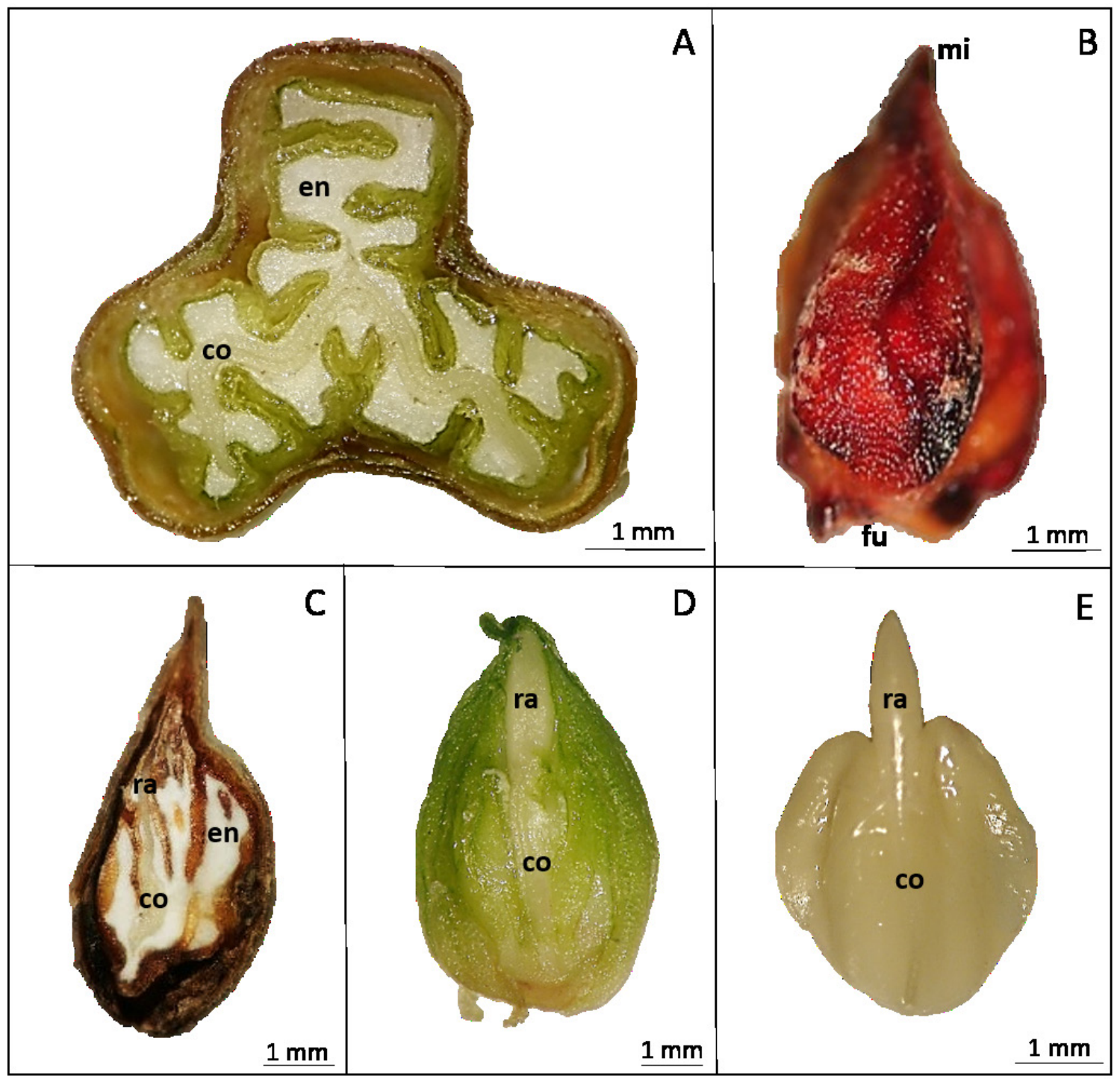

Fig. 6. Fruto, semilla y embrión de $R$. apetala. A: Corte transversal del fruto (aquenio) mostrando endosperma ruminado (en) y los cotiledones plegados (co) en el centro. B: Semilla con episperma de aspecto papiloso, derivada de óvulo ortótropo con micrópilo (mi) y funículo (fu) opuestos. C: Corte longitudinal del aquenio, se observa el endosperma (en), el embrión con la radícula (ra) y los cotiledones (co). D: Corte longitudinal de la semilla. E: Vista superficial del embrión con cotiledones foliáceos.

Fig. 6. Fruit, seed and embryo of $R$. apetala. A: Cross section of the fruit (achene) showing ruminated endosperm (en) and folded cotyledons (co) in the center. B: Seed with papillose appearance episperm, derived from orthotropic ovule with micropyle (mi) and funiculus (fu) opposite. C: Longitudinal section of the achene, it is observed the endosperm (en), the embryo with the radicle (ra) and the cotyledons (co). D: Longitudinal section of the seed. E: Surface view of the embryo with foliaceous cotyledons.

de paredes gruesas subyacentes al epicarpo reaccionan positivamente con el verde rápido (Fig. 8C), señalando la zona de movimiento del agua hacia el interior del lóculo. Estas observaciones concuerdan con las realizadas en el fruto de Olea europea L. por Voyiatzis (1992), quien identificó que el agua ingresa a las drupas por la sutura ventral del carpelo. 

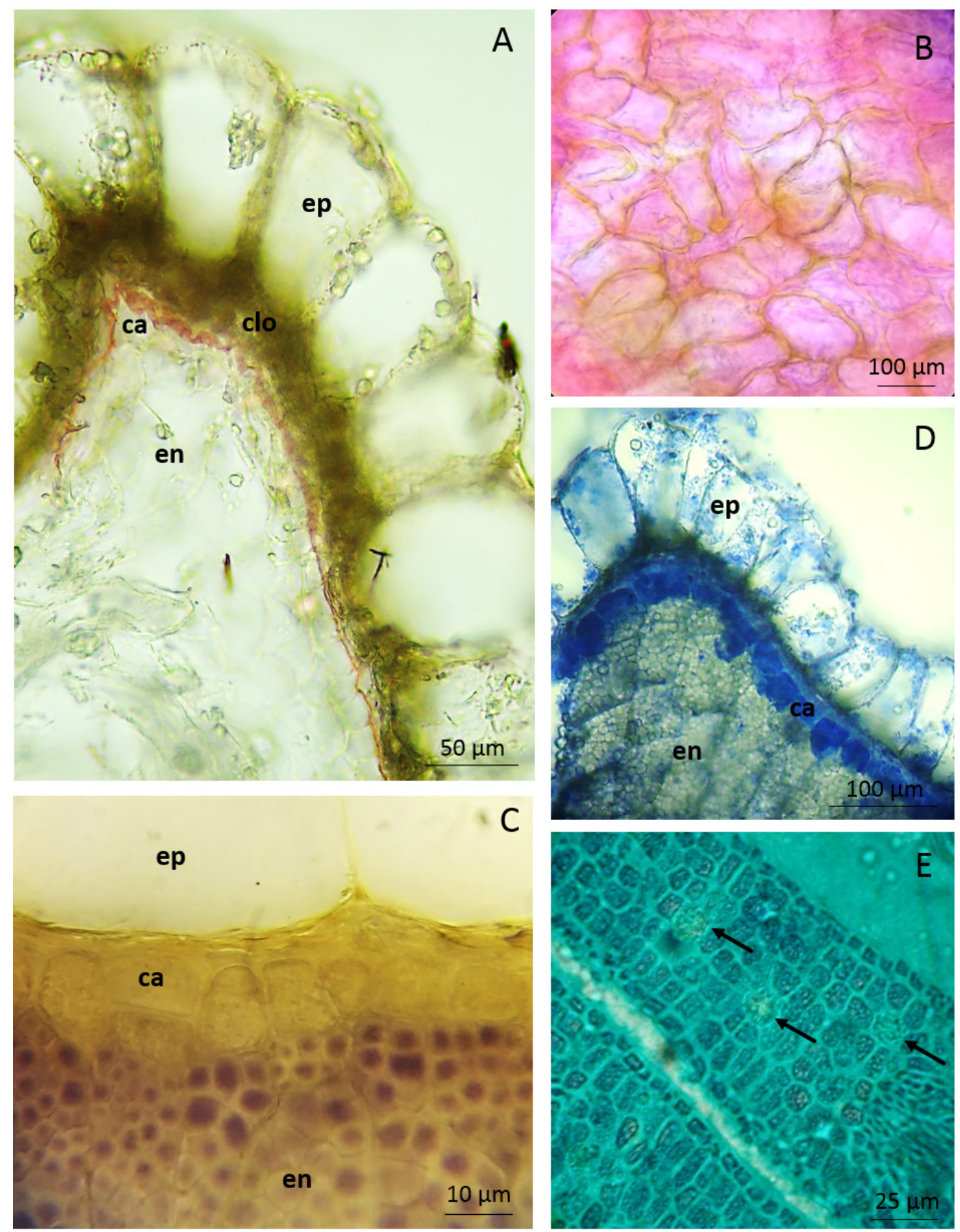

Fig. 7. Caracteres anatómicos de la semilla de $R$. apetala. A: Corte transversal mostrando células del episperma de forma papilosa (ep), clorénquima (clo), capa de aleurona (ca) y endosperma (en). B: Episperma en vista superficial con células de paredes delgadas. C: Endosperma con reservas de almidón, en transcorte. D: Corte transversal en la zona de la capa de aleurona. E: Cotiledones con cristales (flechas) en transcorte del embrión.

Fig. 7. Anatomical characters of the seed of R. apetala. A: Cross section showing papillose episperm cells (ep), chlorenchyma (clo), aleurone layer (ca) and endosperm (en). B: Episperm in superficial view with thin-walled cells. C: Endosperm with starch reserves, in transection. D: Cross section in the aleurone layer zone. E: Cotyledons with crystals (arrows) in transection of the embryo. 
También se observa la coloración a lo largo del haz vascular desde el pedicelo, el cual permanece unido al aquenio, continuando por el funículo, hasta su punto de terminación en la chalaza de la semilla (Fig. 8D). La hipóstasis localizada en la chalaza, está constituida por un grupo de células bien diferenciadas y dispuestas en 5 a 11 capas compactas que adoptan la forma de plato (Fig. 8E). Estas células son angulares $\mathrm{y}$ poseen contenidos rojizos a marrones que viran al verde en presencia del sulfato férrico, lo que indica la presencia de taninos (Fig. 8F). Las características mencionadas concuerdan con las encontradas en la semilla de Ribes multiflorum por Mattana et al. (2012). Estos autores no observaron tinción en la hipóstasis con la solución de azul de metileno, debido a la presencia de taninos en las células que evitan la entrada de la solución y actúan como un tapón chalazal.

En la región micropilar de la semilla de $R$. apetala se observa que la epístasis está constituida por células suberizadas que obstruyen el micrópilo, las cuales permanecieron incoloras durante el período de imbibición con el verde rápido (Fig. 8G), a diferencia de lo informado por Mattana et al. (2012) en Ribes multiflorum.

Las células de la capa más externa del tegumento seminal se colorearon de celeste, lo que indicaría que el agua difunde a través de episperma.

Después de 15 días del comienzo de la imbibición en la solución de verde rápido, el endosperma y el embrión aún permanecieron sin teñir (Fig. 8E, G-H), pero mostraron evidencias visuales del ingreso del agua en sus tejidos. Estos resultados son semejantes a los descriptos por Mattana et al. (2012), quienes sugieren que algunos métodos de tinción son aproximaciones indirectas, ya que la cubierta seminal presenta distinto comportamiento frente al agua (peso molecular: 18,015 g/mol), en contraste con otros colorantes que poseen moléculas de mayor tamaño (verde rápido: $808,843 \mathrm{~g} / \mathrm{mol})$.

En el fruto colocado en agua, las observaciones realizadas a las $24 \mathrm{~h}$, mostraron evidencias de que la imbibición del endosperma ocurre por el agua que ingresa a través de las células del episperma subyacente. Las zonas periféricas del endosperma se observaron grises debido al mayor contenido de agua, mientras que el endosperma cercano al embrión permanecía aún blanco (Fig. 8I).

\section{Ensayos de germinación}

Los aquenios con sépalos (ACS) incubados a temperatura constante de $25^{\circ} \mathrm{C}$ o alternante a $20<=>30^{\circ} \mathrm{C}$ y los aquenios sin sépalos (ASS) a temperatura alternate $20<=>30^{\circ} \mathrm{C}$, ambos casos bajo un fotoperíodo de $8 / 16 \mathrm{~h}$, exhiben $84 \%$ de germinación, siendo significativamente diferentes al 65\% de germinación logrado en las semillas sensu stricto (SE) incubadas a $25^{\circ} \mathrm{C}$ constante y oscuridad permanente (Tabla 1). Estos valores se encuentran dentro del mismo rango informado por Funes et al. (2009), quienes reportaron valores de germinación entre el 63 y $80 \%$ para "semillas intactas" de $R$. apetala incubadas a $25<=>15^{\circ} \mathrm{C}$ o $35<=>20^{\circ} \mathrm{C}$ y un fotoperíodo de $12 / 12 \mathrm{~h}$ u oscuridad permanente, sin registrarse diferencias significativas entre las diferentes condiciones de germinación. Sin embargo, no especifican qué tratamiento realizaron para extraer el pericarpo y qué estructura consideran como "semilla intacta".

Por su parte, las SE alcanzaron valores de germinación entre 65 y $77 \%$, sin registrarse diferencias significativas para ninguna de las combinaciones de temperaturas y fotoperíodos evaluados en este estudio. Estos resultados son semejantes a los obtenidos por Pais Boch et al. (2012) con SE de $R$. apetala, quienes informaron valores entre 60 y $70 \%$ de germinación cuando las semillas se incubaron a $25<=>15^{\circ} \mathrm{C}$ o $35<=>20^{\circ} \mathrm{C}$, bajo un fotoperíodo de 12/12h. También concuerdan con los porcentajes registrados por Soriano et al. (2011) en semillas de $R$. fusca $(71,7 \%$ de germinación) a $25<=>30^{\circ} \mathrm{C}$ con un fotoperíodo de $12 / 12 \mathrm{~h}$.

Se destaca que el 69 y $65 \%$ de germinación alcanzados por las $\mathrm{SE}$ a $25^{\circ} \mathrm{C}$, con un fotoperíodo de $8 / 16 \mathrm{~h}$ y OP respectivamente, son cercanos al $63 \%$ obtenido en los ensayos con los frutos de $R$. laxiflora en condiciones semejantes $\left(25-27^{\circ} \mathrm{C}\right.$ y fotoperíodo de $\left.12 / 12 \mathrm{~h}\right)$ por Alzugaray et al. (2007) y Alzugaray \& Carnevale (2009). Esta similitud se podría explicar al considerar que estos autores 

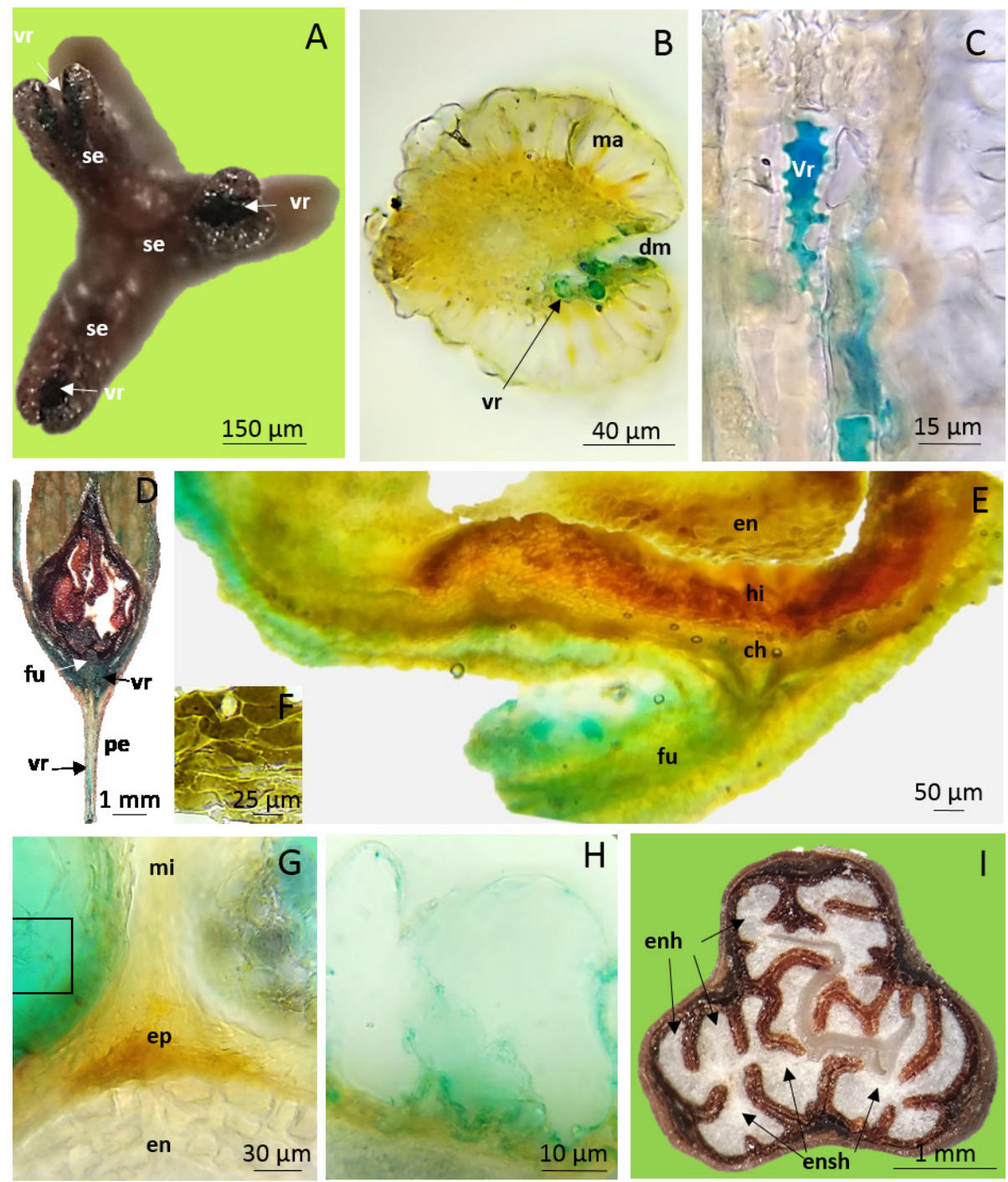

Fig. 8. Entrada del agua en el fruto y la semilla de $R$. apetala sumergidos en verde rápido (A-H) y agua (I). A: Vista superficial del aquenio con restos de los tres estilos, se observan las suturas de los estilos (se) y las flechas indican las aberturas teñidas con verde rápido (vr). B: Corte transversal del estilo con discontinuidad (dm) en la capa de macroesclereidas (ma). C: Corte longitudinal del estilo mostrando células subyacentes al epicarpo teñidas con verde rápido. D: Corte longitudinal del aquenio con pedicelo (pe) y funículo (fu) teñidos. E: Corte longitudinal de la semilla en la zona de la chalaza (ch), con el funículo teñido y el endosperma (en) y la hipóstasis (hi) sin teñir. F: Células de la hipóstasis con taninos. G: Corte longitudinal de la región del micrópilo (mi), se observa epístasis (ep). H: Detalle del recuadro en G, mostrando células del episperma. I: Corte transversal del fruto con endosperma hidratado (enh), hacia el centro endosperma sin hidratar (ensh).

Fig. 8. Water entry in the fruit and the seed of Ruprechtia apetala submerged in fast green (A-H) and water (I). A: Surface view of the achene with remains of the three styles, the sutures of the styles are observed (se) and the arrows indicate the openings stained with fast green (vr). B: Cross section of the style with discontinuity (dm) in the macroesclereid layer (ma). C: Longitudinal section of the style showing cells underlying the epicarp stained with fast green. D: Longitudinal section of the achene with pedicel (pe) and funiculus (fu) stained. E: Longitudinal section of the seed in the chalazal area (ch), with the stained funiculus and the endosperm (en) and the hypostase (hi) without staining. F: Hypostase cells with tannins. G: Longitudinal section of the micropyle region (mi), epistase (ep) is observed. H: Detail of the box in G, showing episperm cells. I: Cross section of the fruit with hydrated endosperm (enh), towards the endosperm center without hydrating (ensh). 
Tabla 1. Porcentaje de germinación de aquenios con sépalos (ACS), aquenios sin sépalos (ASS) y semillas sensu stricto (SE) de $R$. apetala luego de 35 días de la siembra e incubación bajo distintos regímenes de temperatura y luz.

Table 1. Germination percentage of achenes with sepals (ACS), achenes without sepals (ASS) and seeds sensu stricto

(SE) of $R$. apetala 35 days after sowing and incubation under different temperature and light regimes.

\begin{tabular}{|ccccccc|}
\hline & \multicolumn{2}{c}{ ACS } & \multicolumn{2}{c}{ ASS } & \multicolumn{2}{c|}{ SE } \\
\hline & $25^{\circ} \mathrm{C}$ & $20^{\circ} \mathrm{C} \circ 30^{\circ} \mathrm{C}$ & $25^{\circ} \mathrm{C}$ & $20^{\circ} \mathrm{C} \circ 30^{\circ} \mathrm{C}$ & $25^{\circ} \mathrm{C}$ & $20^{\circ} \mathrm{C} \circ 30^{\circ} \mathrm{C}$ \\
$\begin{array}{c}\text { Fotoperíodo L/O } \\
\text { (8/16h) }\end{array}$ & $84 \% \mathrm{~b}$ & $84 \% \mathrm{~b}$ & $81 \% \mathrm{ab}$ & $84 \% \mathrm{~b}$ & $69 \% \mathrm{ab}$ & $77 \%$ ab \\
OP & $78 \% \mathrm{ab}$ & $79 \% \mathrm{ab}$ & $73 \% \mathrm{ab}$ & $79 \% \mathrm{ab}$ & $65 \% \mathrm{a}$ & $75 \% \mathrm{ab}$ \\
\hline
\end{tabular}

Letras diferentes indican diferencias significativas entre tratamientos para $\mathrm{P}<0,05$. L: Luz; O: Oscuridad; OP: Oscuridad permanente.

realizaron un pretratamiento rompiendo el extremo de los aquenios, condición similar a las SE con extracción del pericarpo. En ambos casos se favorece el ingreso del agua en la semilla con los consiguientes resultados en la germinación.

Al comparar el efecto de la variable temperatura, no se observaron diferencias significativas en los porcentajes de germinación, considerando una misma condición lumínica. Así en los ACS no hay diferencias significativas, mientras que los valores obtenidos en cada condición térmica se van alejando entre sí en los ASS y en las SE. En estos últimos casos prevalecen los valores más favorables en la condición de alternancia de temperaturas en concordancia con Baskin \& Baskin (2014).

El efecto de la luz se manifestó con valores más altos de porcentaje de germinación con fotoperíodo $8 / 16 \mathrm{~h}$ que con los obtenidos en $\mathrm{OP}$, en las dos condiciones de temperaturas ensayadas. Sin embargo tampoco presentan

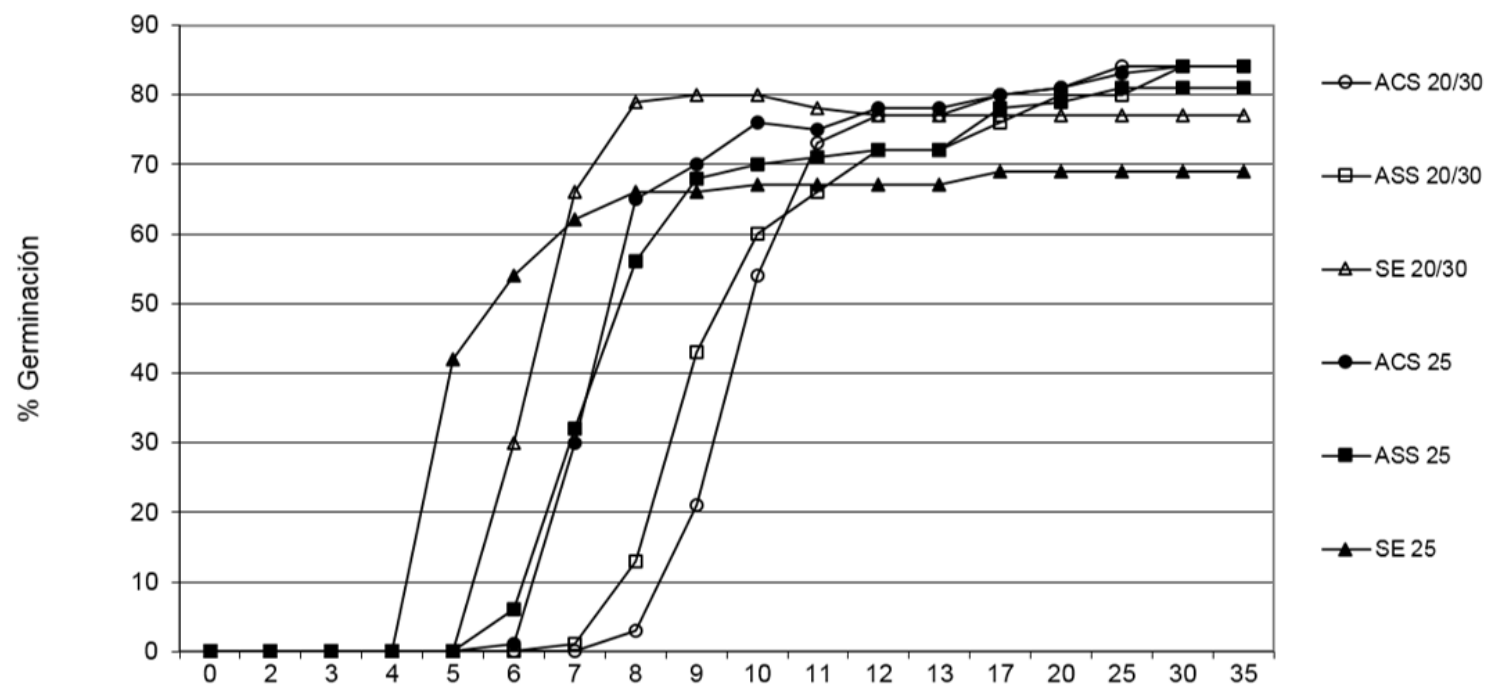

Días después de la siembra (DDS)

Fig. 9. Porcentaje de germinación acumulada durante 35 días, de aquenios con sépalos (ACS), aquenios sin sépalos (ASS) y semillas sensu stricto (SE) de $R$. apetala en diferentes condiciones de temperatura y luz.

Fig. 9. Germination percentage accumulated during 35 days, of achenes with sepals (ACS), achenes without sepals (ASS) and seeds sensu stricto (SE) of $R$. apetala under different temperature and light conditions. 
diferencias significativas, y concuerdan con los resultados logrados por Funes et al. (2009), quienes indican que $R$. apetala no tiene semillas fotosensibles para la germinación.

Al analizar la influencia de las estructuras extraováricas, los valores más bajos de porcentaje de germinación son obtenidos en las SE (65-77\%) en comparación con los restantes tratamientos de ACS y ASS (73 y 84\%). Esto podría deberse a la dificultad de obtener semillas indemnes durante el proceso de separación del aquenio. Dicha operación, que se ve dificultada por el tamaño reducido del fruto, la ubicación de la semilla contigua al pericarpo y su consistencia coriácea, puede provocar daños en el embrión y comprometer su viabilidad.

Finalmente, se destacan los valores obtenidos en los ACS y ASS, con porcentajes de germinación superiores al 84\%, los cuales demuestran que el pericarpo y los sépalos no constituyen un impedimento para la germinación.

Por otro lado, al observar el porcentaje de germinación acumulado durante el tiempo en los diferentes tratamientos (Fig. 9), las SE poseen las tasas de germinación inicial más altas (con valores cercanos al $60 \%$ en el sexto día), mientras que los restantes tratamientos de ACS y ASS, tienen tasas de germinación inicial inferiores al $10 \%$ en el sexto día. En las SE, al extraer el pericarpo, se acorta el camino del agua hacia el embrión, lo que se traduce en la reducción del tiempo para la germinación. Así, el 50\% de germinación (G 50) se alcanza entre los 5-6 días después de la siembra (DDS) en el tratamiento $\mathrm{SE}$ a $25^{\circ} \mathrm{C}$, mientras que para los ACS se alcanza a los 7-9 DDS.

\section{Conclusiones}

En este trabajo se aportan características morfológicas novedosas del aquenio de $R$. apetala, como son la presencia de macroesclereidas no lignificadas y los taninos en el lumen de las mismas, reveladas en el pericarpo y la presencia de amiloplastos en el mesocarpo. En la semilla, se corrobora la presencia de la epístasis e hipóstasis, de la capa de aleurona del endosperma y de cristales en el mesofilo de los cotiledones. En relación a la vía de entrada del agua en el fruto, se identificó que el ingreso se produce por los restos de los estilos, en la zona de la sutura ventral de los tres carpelos y en la semilla a través del tegumento seminal.

Se demostró que el pericarpo y los sépalos persistentes no constituyen un impedimento para la germinación. La opción más eficiente para realizar ensayos de poder germinativo de esta especie, es la de los aquenios con sépalos, tanto a $25^{\circ} \mathrm{C}$ como a $20<=>30^{\circ} \mathrm{C}$, con un fotoperíodo de 8/16h y, en segundo lugar, la condición de oscuridad permanente.

Además se demuestra que las semillas sensu estricto poseen mayor sensibilidad ante las condiciones de temperatura y luz, expresada en menores porcentajes de germinación, y se refuerza la idea de que el pericarpo protege al embrión de las influencias ambientales y que el aquenio actúa como una unidad funcional, optimizando la germinación. La información lograda con estos resultados es un aporte al conocimiento de los factores que controlan la germinación de uno de los árboles del bosque nativo.

\section{Agradecimientos}

A la Dra. Patricia Perissé por sus aportes respecto a las consultas metodológicas, el análisis de resultados y la lectura crítica del manuscrito con las numerosas sugerencias para mejorarlo. Al Centro de Excelencia en Productos y Procesos de Córdoba (CEPROCOR), por el apoyo brindado en la investigación y trabajos de campo, al Laboratorio de Análisis de Semillas (LASIDYS) y al Laboratorio de Microscopía Óptica del Centro Tecnológico Botánica Agronómica (CTBA) de la Facultad de Ciencias Agropecuarias de la Universidad Nacional de Córdoba por brindar los espacios para el trabajo de laboratorio. Se agradece a los revisores anónimos por sus valiosos comentarios y sugerencias.

\section{Bibliografía}

ABRAHAM DE NOIR, F. \& S. BRAVO. 2014. Frutos de leñosas nativas de Argentina. Parte 1. Chaco Occidental y Serrano. 1 $1^{\text {a }}$ ed. Universidad Nacional de Santiago del Estero UNSE. Facultad de Ciencias Forestales. 194 pp. 
ALZUGARAY, C. \& N. CARNEVALE. 2009. Libro de semillas de especies leñosas autóctonas. (Chaco Húmedo, Cuña Boscosa Santafesina). Ministerio de aguas, Servicios Públicos y Medio Ambiente. Secretaría de Medio Ambiente. Santa Fe. Argentina. Acosta Hnos. S.H. 112 pp.

ALZUGARAY, C., N. CARNEVALE, A. SALINAS, L. MORENO \& J. BOGGIO 2007. Calidad de semillas de árboles y arbustos autóctonos de la cuña boscosa santafesina. Análisis de Semillas (INTA) 1: 99-104.

BARBOZA, G. E., J. J. CANTERO, C. O. NÚÑEZ \& L. ARIZA ESPINAR (eds.). 2006. Flora Medicinal de la Provincia de Córdoba (Argentina). Pteridófitas y Antófitas silvestres o naturalizadas. Museo Botánico Córdoba. Gráficamente ediciones. Córdoba, Argentina. $1250 \mathrm{pp}$.

BASKIN, C. C. \& J. M. BASKIN. 2001. Some procedures for dormancy break and germination of difficult seeds. Native Plant Propagation and Restoration Strategies. Oregon State University Nursery Technology Cooperative and Western Forestry and Conservation Association: 12-13.

BASKIN, C. C. \& J. M. BASKIN. 2014. Seeds: Ecology, biogeography and evolution of dormancy and germination. $2^{\circ}$ Ed. Academic Press. San Diego, EE.UU. 1586 pp.

CABRERA, A. 1971. Fitogeografía de la Argentina. Bol. Soc. Argent. Bot. 14: 1-50.

CÉSERE, S. M., A. R. MEEHAN \& M. N. BOETTO. 1998. Plantas nativas. Su uso en espacios verdes urbanos. Ed. Eudecor. Córdoba, Argentina. 95 pp.

COCUCCI, A. E. 1961. Revisión del género Ruprechtia (Polygonaceae). Kurtziana 1: 217-269.

COCUCCI, A. E. 1997. Ruprechtia. En HUNZIKER A. T. (ed.), Fl. Fanerog. Argent. Programa Proflora (CONICET). Museo Botánico, IMBIV. Córdoba, Argentina. 43: 39-41.

CORNER, E. J. H. 1976. The seeds of dicotyledons. Vols. I y II. Cambridge University Press. New York, U.S.A. 324 pp.

CRONQUIST, A. 1977. Introducción a la Botánica. $2^{\circ}$ Ed. CECSA. México. 848 pp.

DE LA PEÑA, M. R. \& J. F. PENSIERO. 2004. Plantas argentinas. Catálogo de nombres comunes. L.O.L.A. Buenos Aires, Argentina. 373 pp.

DEL VitTO, L. A., E. M. PETENATTI \& M. E. PETENATTI. 1997. Recursos herbolarios de San Luis (República Argentina) primera parte: plantas nativas. Multequina 6: 49-66.

DEMAIO, P., U. KARLIN \& M. MEDINA. 2002. Árboles nativos del centro de Argentina $1^{\circ} \mathrm{Ed}$. L.O.L.A. Córdoba, Argentina. 185 pp.

DI RIENZO, J. A., F. CASANOVES, M. G. BALZARINI, L. GONZALEZ, M. TABLADA \& C. W. ROBLEDO. 2013. InfoStat versión 2013. Córdoba: Grupo InfoStat, Facultad de Ciencias Agropecuarias. Universidad Nacional de Córdoba, Argentina.
ESAU, K. 1982. Anatomía de las plantas con semilla. Buenos Aires. Hemisferio Sur. 512 pp.

EVERT, R. F. 2006. Esau Anatomía vegetal. Meristemas, células y tejidos de las plantas: su estructura, función y desarrollo. $3^{\circ}$ ed. Omega. Barcelona. 614 pp.

FAHN, A. 1978. Plant anatomy. Oxford. Blume. Madrid. $620 \mathrm{pp}$.

FUNES, G., S. DÍAZ \& P. VENIER. 2009. La temperatura como principal determinante de la germinación en especies del Chaco seco de Argentina. Ecol. Austral 19: 129-138.

GAMA-ARACHCHIGE, N. S., J. M. BASKIN, R. L. GENEVE \& C. C. BASKIN. 2013. Identification and characterization of ten new water gaps in seeds and fruits with physical dormancy and classification of water-gap complexes. Ann. Bot. 112: 69-84.

GAVIER, G. I. \& E. H. BUCHER. 2004. Deforestación de las Sierras Chicas de Córdoba (Argentina) en el período 1970-1997. Miscelánea No 101. Academia Nacional de Ciencias, Córdoba.

GBIF SECRETARIAT. 2016. Ruprechtia apetala Wedd. GBIF Backbone Taxonomy. Checklist. Disponible en: https://doi.org/10.15468/39omei. (Consulta: 05-10-2017).

ISTA. 2017. International Seed Testing Association. International Rules for Seed Testing. Bassersdorf, Switzerland.

IUCN. 2017. The IUCN Red List of Threatened Species. Versión 2017-2. Disponible en: http://www. iucnredlist.org/search. (Consulta: 20-11-2017).

JOSEAU, M. J., S. D. ARÁOZ \& R. A. HERNÁNDEZ. 2013. La semilla. En JOSEAU M. J., M. Y. CONLES \& G. E. VERZINO (eds.), Conservación de recursos forestales nativos de Argentina. El cultivo de plantas leñosas en vivero y a campo, pp. 53-90. Ed. Brujas. Córdoba.

MAITI, R., H. GONZALEZ RODRIGUEZ \& N. SERGEEVNA IVANOVA. 2016. Autoecology and Ecophysiology of Woody Shrubs and Trees. Concepts and Applications. John Wiley \& Sons. UK. 368 pp.

MARINO, G. D., M. V. MAS \& M. J. ORLANDONI. 2008. Morfología y reconocimiento de las principales especies leñosas nativas de la provincia de Santa Fe, Argentina, en el estado de plántula. Bol. Soc. Argent. Bot. 43: 67-81.

MARTIN, A. C. 1946. The comparative internal morphology of seeds. Amer. Midl. Naturalist 36: 513-660.

MATTANA, E., H. W. PRITCHARD, M. PORCEDDU, W. H. STUPPY \& G. BACCHETTA. 2012. Interchangeable effects of gibberellic acid and temperature on embryo growth, seed germination and epicotyl emergence in Ribes multiflorum ssp. sandalioticum (Grossulariaceae). Plant Biol. 14: 77-87. 
MELO, E. DE. 2015. Polygonaceae in Lista de Espécies da Flora do Brasil. Jardim Botânico do Rio de Janeiro. Disponible en: http://floradobrasil.jbrj.gov.br/jabot/ floradobrasil/FB20603. (Consulta: 05-10-2017).

MORELLO, J. \& A. F. RODRIGUEZ (eds.). 2009. El Chaco sin bosques: la Pampa o el desierto del futuro. Orientación Gráfica Editora. Buenos Aires. 432 pp.

MUNSELL, A. H. 2000. Munsell soil color charts. Munsell Color Company, I.N.C., Baltimore, Maryland. USA. $55 \mathrm{pp}$.

NIEMBRO ROCAS, A. 1989. Semillas de plantas leñosas. Morfología comparada. Ed. Limusa. D. F., México. 224 pp.

NÚÑEZ, C. \& J. J. CANTERO. 2000. Las Plantas Medicinales del Sur de la Provincia de Córdoba. Ed. Fundación Universidad Nacional de Río Cuarto. Córdoba, Argentina. 144 pp.

PAIS BOSCH, A., P. TECCO, G. FUNES \& M. CABIDO. 2012. Efecto de la temperatura en la regeneración de especies leñosas del chaco serrano e implicancia en la distribución actual y potencial de bosques. Bol. Soc. Argent. Bot. 47: 401-410.

PARODI, L. R. 1978. ( $3^{\mathrm{a}}$ ed ampliada y actualizada por M. J. Dimitri) Enciclopedia Argentina de Agricultura y Jardinería. Tomo I, Vol. $1^{\circ}$ y $2^{\circ}$. Acme Agency. Buenos Aires.

PERIASAMY, K. 1962. Studies on seeds with ruminate endosperm. Development of rumination in the Vitaceae. Proc. Indian Acad. Sci. B 56: 13-26.

PONS, S. M. 2015. Guía de Reproducción de Árboles Nativos de Córdoba para jardinería. SIMA. Córdoba. 120 pp.

SORIANO, D., A. OROZCO-SEGOVIA, J. MÁRQUEZGUZMÁN, K. KITAJIMA, A. GAMBOA-DE BUEN \& P. HUANTE. 2011. Seed reserve composition in 19 tree species of a tropical deciduous forest in Mexico and its relationship to seed germination and seedling growth. Ann. Bot. 107: 939-951.
SPJUT, R. W. 1994. A systematic treatment of fruit types. Memoirs of the New York Botanical Garden. New York, USA. 70: 1-182.

UMSEF. UNIDAD DE MANEJO DEL SISTEMA DE EVALUACIÓN FORESTAL Dirección de Bosques. 2016. Monitoreo de la superficie de bosque nativo de la República Argentina. Regiones forestales Parque Chaqueño, Yungas, Selva Paranaense y Espinal. Período 2014-2015. $2^{\circ}$ Ed. Ministerio de Ambiente y Desarrollo Sustentable. Presidencia de la Nación.

VERZINO, G. E., R. A. HERNÁNDEZ, A. R. MEEHAN, M. J. JOSEAU, D. H. OSÉS, J. E. FRASSONI, G. CLAUSEN, C. E. SALGADO, E. E. SOSA, A. P. CISTERNAS \& S. S. SÁNCHEZ. 2016. Flora del bosque nativo del centro de Argentina. Valor paisajístico, tintóreo y apícola. Encuentro Grupo Editor. Córdoba. 167 pp.

VOLKMANN, L. R. \& R. SUAREZ. 2008. Reforestación en el ambiente serrano. Disponible en: http://www. uepc.org.ar/conectate/wp-content/uploads/2013/04/ Volkmann-Suarez-2008_Boletin-bosque-serrano-

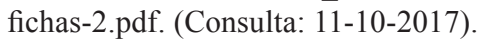

VOYIATZIS, D. G. 1992. The pathway of water entry into olive (Olea europaea), stones. Seed Sci. \& Technol. 20: 715-717.

WERKER, E. 1997. Seed Anatomy. Ed. Gebrüder Borntraeger. Berlin. 423 pp.

ZARLAVSKY, G. E. 2014. Histología vegetal, técnicas simples y complejas. $1^{\circ} \mathrm{ed}$. SAB. Buenos Aires, Argentina. 198 pp.

ZULOAGA, F. O., O. MORRONE \& M. J. BELGRANO. 2011. Catálogo de las Plantas Vasculares del Cono Sur. Argentina. Disponible en: http://www.darwin. edu.ar/Proyectos/FloraArgentina/DetalleEspecie. asp ? forma $=\&$ variedad $=\&$ subespecie $=\&$ especi $\mathrm{e}=$ apetala\&genero=Ruprechtia\&espcod $=21297$. (Consulta: 02-10-2017).

Original recibido el 21 de noviembre de 2017; aceptado el 1 de marzo de 2018. 